or personal limitations such as inadequate understanding." ${ }^{16}$ It confers an obligation on healthcare providers to be truthful and to respect the choices that their patients make.

Our patient currently does not need to make any decisions about her physical treatment. Her gonads have been removed, and she is no longer at risk of malignancy. She has been taking oestrogen daily, and her bone density is within normal limits. Nevertheless, knowing about her genetic make-up might enable her to exercise choices in other aspects of her life. She could, for example, choose to share information about this $\mathrm{X}$ linked condition with other members of her family.

An argument could be made for non-disclosure if she were not able to function autonomously. If she was intellectually disabled or had an acute psychiatric condition, she would have limited capacity for information processing and self determination. The clinical psychologist described her as being too fragile to be told about her genotype, but there does not seem to be any evidence that this is still the case.

Respect for patient autonomy would also allow the diagnosis to be withheld if the patient did not want to know. But she does not know that there is something to disclose. Unless we tell her, we cannot find out whether she wants to know. We have no evidence that she does not want to find out about her underlying diagnosis-the fact that she has expressed confusion about her absent uterus indicates that the reverse is likely to be true.

\section{Justice}

Justice is in its broadest sense about equality and fairness. ${ }^{15}$ It raises several issues pertinent to this case. In terms of equality, it suffices to apply Rawls' strategy of asking what we would want to happen if the positions were reversed. ${ }^{6}$ Our patient deserves respect and it is only fair that she be told her genotype similar to anyone else in her situation; the sensitive nature of her condition does not abrogate the obligation to disclose. In addition, it is only fair that she is given access to the clinical expertise of her healthcare providers who can inform her sensitively. In terms of distributive justice, sufficient resources are available; other patients will not be deprived of medical care if time is allocated to her.

\section{Decision}

Any obligation to respect the decisions of the previous healthcare providers is clearly over-ridden by the ethical principles of justice and respect for patient autonomy. The argument that disclosure would lead to unacceptable harm is no longer valid. Unquestionably, the great- est harm would result if the patient found out her diagnosis by chance in an unsupported environment. The probability of this happening through modern information technology is high. The harm associated with disclosure, conversely, is likely to be short term and minimised by a sensitive and skilful approach.

When the patient returned to clinic, the doctor asked whether she had ever been curious to know why she did not have a uterus. She said yes, quickly adding that she was sure that information had been withheld in the past. He arranged for her to see a clinician with expertise in dealing with intersex conditions. She was initially extremely angry when told about her genotype, but knowing about it has led to a positive outcome. She continues to attend for regular follow up.

The series is edited by Michael Parker, reader in medical ethics at the Ethox Centre, University of Oxford (michael.parker@ethox.ox.ac.uk) and Julian Savulescu of the Oxford Uehiro Centre for Practical Ethics. We thank the patient for supporting the writing of the paper and Jeanette Lawrence for her helpful comments.

Contributors and sources: JC is a consultant endocrinologist and a medical educator. LG is a medical ethicist with broad experience in clinical ethical issues and a particular interest in genetics. GC is a consultant endocrinologist with an interest in the management of intersex conditions in adulthood. This article arose from discussions at a clinical meeting on how to approach the issue of disclosure in complete androgen insensitivity syndrome in adulthood.

Competing interests: None declared.

1 Morris JM. The syndrome of testicular feminization in male pseudohermaphrodites. Am J Obstet Gynecol 1953;65:1192-211.

Jagiello G, Atwell JD. Prevalence of testicular feminisation. Lance 1962;i:329.

3 Blackless M, Charuvastra A, Derryck A, Fausto-Sterling A, Lauzanne K, Lee E. How sexually dimorphic are we? Review and synthesis. Am J Hum Biol 2000;12:151-66.

4 Bangsboll S, Qvist I, Lebech PE, Lewinsky M. Testicular feminisation syndrome and associated gonadal tumours in Denmark. Acta Obstet Gynecol drome and associa

5 Weiner JS, Teague JL, Roth DR, Gonzales ET, Lamb DJ. Molecular biology and function of the androgen receptor in genital development. J Uro 1997:157:1377-86

6 Beauchamp TL, Childress JF. Principles of biomedical ethics. 5th ed. New York: Oxford University Press, 2001.

7 Kerridge I, Lowe M, McPhee J. Ethics and law for the health professions. 2nd ed. Sydney: Federation Press, 2005.

Minogue BP, Taraszewski R. Commentary: the whole truth and nothing but the truth? Hastings Cent Rep 1988;18(5):34-5.

Shah R, Woolley MM, Costin G. Testicular feminization: the androgen insensitivity syndrome. J Pediatr Surg 1992;27:757-60.

10 Drensitity AD Ambinous ox or anbivalent medicine? Dreger AD. Ambiguous sex or ambivalent medicine? Ethical iss
treatment of intersexuality. Hastings Cent Rep 1998;28(3):24-35.

treatment of intersexuality. Hastings Cent Rep 1998;28(3):24-35. Hereditas Pettersson G,

1937;23:49-69.
Kemp BD. Sex, lies and androgen insensitivity syndrome. CMAJ 1996; $154: 1829$.

13 Ahlquist JO. Gender identity in testicular feminisation. BMJ 1994;308 1042 .

14 Kemp BD. Sex, lies and androgen insensitivity syndrome [letter]. CMAJ $1996 ; 154: 1829$.

15 Kitchener KS. Foundation principles of ethical practice, research and teaching in psychology. Mahwah, NJ: Lawrence Erlbaum, 2000.

(Accepted 8June 2005)

\title{
War wound
}

About 10 years ago I was asked to see a man in his 90 s with symptoms of "piles." He was relatively fit and mentally alert, so he was able to give me the longest and most accurate history of onset that I have ever had.

He told me his problems had begun with constipation, which he had while serving with his regiment at the battle of the Somme in 1916-the trench latrines had been destroyed by shellfire. In 1919, after he had been discharged from the army, he consulted a doctor, who advised him that surgery could not be recommended and that he should continue to use the cream. He did so for more than 70 years until he went into care. Fortunately, a couple of elastic bands relieved his symptoms.

Could his chronic long term disability be described as a battle injury?

William Mair retired consultant surgeon, Castle Cary, Somerset 